\title{
Effects of Exogenous Microbial Agents on Soil Nutrient and Microbial Community Composition in Greenhouse-Derived Vegetable Straw Composts
}

\author{
Cuixia Yun ${ }^{1,2}$, Changrong Yan ${ }^{1,2}$, Yinghao Xue ${ }^{3}$, Zhiyu $\mathrm{Xu}^{3}$, Tuo Jin ${ }^{3, *}$ and Qin Liu ${ }^{1,2, *}$ (1) \\ 1 Institute of Environment and Sustainable Development in Agriculture, Chinese Academy of Agricultural \\ Sciences, Beijing 100081, China; yuncuixia2020@163.com (C.Y.); yanchangrong@caas.cn (C.Y.) \\ 2 Key Laboratory of Prevention and Control of Residual Pollution in Agricultural Film, Ministry of Agriculture \\ and Rural Affairs, Beijing 100081, China \\ 3 Rural Energy \& Environment Agency, Ministry of Agriculture and Rural Affairs, Beijing 100125, China; \\ xueyinghao@agri.gov.cn (Y.X.); xufanjin@126.com (Z.X.) \\ * Correspondence: jintuo273@126.com (T.J.); liuqin02@caas.cn (Q.L.); Tel./Fax: +86-10-82109773 (Q.L.)
}

Citation: Yun, C.; Yan, C.; Xue, Y.; Xu, Z.; Jin, T.; Liu, Q. Effects of Exogenous Microbial Agents on Soil Nutrient and Microbial Community Composition in Greenhouse-Derived Vegetable Straw Composts. Sustainability 2021, 13, 2925. https://doi.org/10.3390/ su13052925

Academic Editor: Silvia Tabacchioni

Received: 13 January 2021

Accepted: 1 March 2021

Published: 8 March 2021

Publisher's Note: MDPI stays neutral with regard to jurisdictional claims in published maps and institutional affiliations.

Copyright: (c) 2021 by the authors. Licensee MDPI, Basel, Switzerland. This article is an open access article distributed under the terms and conditions of the Creative Commons Attribution (CC BY) license (https:// creativecommons.org/licenses/by/ $4.0 /)$.

\begin{abstract}
Vegetable waste causes resource waste and environmental pollution, giving rise to the spread of harmful organisms and causing disease in normal vegetable cultivation. Random distribution of vegetable waste can increase the risk of non-point agricultural pollution and explore the feasibility of its resource utilization. This study was designed to evaluate the effects of different doses of exogenous microbial agents on soil microbial communities after in situ composting of cucumber straw on plots with biodegradable mulch films. The cucumber straw and chicken manure were used as the base materials, and the next generation sequencing was used to analyze changes in the microbiome following composting. The results demonstrate that the addition of exogenous microbial agents had prolonged the high-temperature duration, reduced the total organic carbon (TOC) content, and accelerated the decline in the $\mathrm{C} / \mathrm{N}$ ratio, ensuring compost maturity and effectively shortening the composting time. The predominant bacterial phyla of the four treatment groups were Proteobacteria and Firmicutes; while among fungal phyla, these treatments decreased the relative abundance of Ascomycota. The treatment of $300 \mathrm{t} /$ ha microbial agents significantly increased the richness and diversity of both the bacterial and fungal communities. Redundancy analysis suggested that soil total nitrogen (TN) content had a significant effect on the bacterial community, while TN content, $\mathrm{pH}$, and temperature influenced the fungal community in these samples. Collectively, the treatment of $300 \mathrm{t} / \mathrm{ha}$ exogenous microbial agents improved the quality of composting and promoted microbiome diversity.
\end{abstract}

Keywords: biodegradable mulch films; cucumber straw; chicken manure; microbial agents; microbial communities

\section{Introduction}

Crop straw contains many nutrients, including carbon, nitrogen, phosphorus, and potassium, which can be used to carry matter, energy, and nutrients, serving as a valuable biomass resource [1]. Thus, crop straw plays a critical role in improving soil structure and regulating its water, fertility, gas, heat, and microbial content [2,3]. The annual production of crop straw in China is in excess of 900 million tons, with vegetable straw making up approximately $25.6 \%$ of the total. Vegetable straw is strongly characterized by high moisture content, short storage time, and being difficult to transport. Moreover, if large amounts of vegetable waste are piled at random, it will begin to rot and stink, breeding mosquitoes and flies [4] and spreading germs [5]. Eventually, this mismanagement leads to resource wastage and increased environmental pollution [6]. Effective reapplication of this straw not only accelerates its own decomposition and increases the supply of appropriate nutrients to the soil but also promotes crop growth, regulates soil temperature, preserves 
moisture content, and inhibits the growth of weeds [7]. Straw return can help to maintain farmland fertility, reduce the use of chemical fertilizers, improve soil carbon sequestration, promote the soil nitrogen cycle [8], decrease or avoid environmental pollution caused by straw burning, and promote a virtuous cycle of agricultural production [9].

Recently, plastic film mulching has become a critical agronomic measure used to protect vegetable production by facilitating the transformation of agricultural production modes and deepening agricultural structural adjustments. These films play an important role in regulating soil temperature, preserving water and fertilizer content, inhibiting the growth of weeds, and reducing humidity. However, the increasing use of plastic films has led to many environmental problems [10-12]. These materials are not naturally degraded and can remain in the environment for hundreds of years. Many of these films may never degrade, as they are produced from extremely stable compounds, such as polyethylene or polyvinyl chloride, in China [13]. This is particularly problematic for the ultra-thin plastic film products, as they are easily broken during crop production; consequently, there is limited secondary utilization of these films and reduced recovery of the plastic scraps [14]. This results in their accumulation within the soil and their long-term increase in soil consolidation, seriously hindering the transport of water and nutrients within the soil, destroying the soil ecological environment, and causing a serious reduction in crop yield $[15,16]$. However, these issues may be resolved by the use of biodegradable mulch films, which can be broken down into mineralized inorganic $\mathrm{CO}_{2}$, $\mathrm{H}_{2} \mathrm{O}$, salts and their elements by soil microbes; thus, these films can participate in the natural metabolic cycle $[17,18]$. Cozzolino et al. [19] showed that biodegradable plastic films are a suitable alternative to polyethylene films and bare land cultivation. In addition, the use of biodegradable mulch films helps to reduce incomplete mechanical recycling and reduce the labor associated with removing the film, which is an important part of addressing the current issues around residual film pollution [14].

Many studies have shown that composting using high-temperature aerobic composting techniques is an effective means for improving resource utilization and reducing agricultural and animal husbandry waste $[20,21]$. Agricultural wastes are mineralized and humized, killing pathogenic bacteria during the high-temperature fermentation process and promoting the maturation of organic wastes via the metabolic activities of the associated microbiome [22-24]. However, the number of indigenous microorganisms is often insufficient to facilitate natural compost fermentation, resulting in reduced decomposition, longer fermentation cycles, and reduced nutrient content in composting products. Therefore, the use of microorganism-promoting additives is a safe and effective method to hasten the process of high-temperature composting and improve the ripening quality of the products. These additives include natural adsorbents, such as peat and zeolite [25-28], and exogenous microbial agents [29]. In fact, exogenous microbial agents can accelerate the degradation of agricultural wastes while reducing costs, simplifying operations, and causing no secondary pollution. There are complex changes in the microbial community during composting that affect the quality of the composting processes. Accordingly, the evaluation of microbial community structures has received widespread attention in recent years [30]. Huang et al. [31] showed that the composition of successive microbial communities is directly affected by the physical and chemical indices of the composting process, with temperature being one of the most significant environmental factors affecting the composition of these microbial communities.

Previously, little was known about the effect of research on biodegradable mulch combined with vegetable straw in situ compost. Our hypothesis was based on the degradability of the biodegradable mulch film; cucumber straw and chicken manure were used as the base materials. We evaluated the combination of cucumber straw and biodegradable mulch film that was crushed and returned directly to the field using a straw grinder, following which, it was plowed and treated with exogenous microbial agents designed to encourage high-temperature composting. The effects of the addition of exogenous microbial agents on the nutrients of the pile, the changes of the microbial community, and the metabolic 
function were investigated with the biodegradable mulch film and vegetable straw during greenhouse composting. The major aim of our work was to investigate the effects of exogenous microbial agents on physicochemical properties (including temperature, total organic carbon, total nitrogen, $\mathrm{pH}$, etc.) in the composting process; (2) to investigate the effects of exogenous microbial agents on the diversity of the microbial community structure and the functional diversity during composting; (3) to explore the relationship between predominant soil microflora and environmental factors.

\section{Materials and Methods}

\subsection{Site Description}

These experiments were carried out in a greenhouse $\left(36^{\circ} 51^{\prime} \mathrm{N}, 118^{\circ} 50^{\prime} \mathrm{E}\right)$ in Shouguang City, Shandong Province, China. The area began to return straw to the field in 2017 and completed these procedures twice a year (cucumber-tomato rotation). This area has a warm temperate monsoon climate, with an annual average of 2549 sunshine hours, an average temperature of $12.7^{\circ} \mathrm{C}$, and precipitation of $600-700 \mathrm{~mm}$. The annual evaporation is $1834 \mathrm{~mm}$, with $45-50 \%$ of this evaporation occurring between June and September. The soil $\mathrm{pH}$ was 7.05 , and the total organic carbon (TOC) content was $21.03 \mathrm{~g} / \mathrm{kg}$, with $1.76 \mathrm{~g} / \mathrm{kg}$ of total nitrogen $(\mathrm{TN})$.

\subsection{Materials}

Cucumber residue and dried chicken manure were purchased locally, and the cucumber residue was harvested from previous stubble. The whole volume of cucumber residue was crushed to a size ranging between 3 and $5 \mathrm{~cm}$ into the field using a straw grinder. The basic physicochemical properties of these materials are listed in Table 1. The microbial agent was powdered, and the effective number of living bacteria was 1 billion per gram. These agents predominantly comprised Bacillus subtilis and Bacillus licheniformis.

Table 1. Physicochemical characteristics of the raw materials used in the composting analysis.

\begin{tabular}{ccccc}
\hline Material & WC $(\%)$ & TOC $(\mathbf{g} / \mathbf{k g})$ & TN $(\mathbf{g} / \mathbf{k g})$ & C/N \\
\hline Chicken manure & - & 31.53 & 5.36 & 5.88 \\
Cucumber straw & 76.02 & 39.58 & 2.11 & 18.76 \\
\hline
\end{tabular}

Note: WC: water content; TOC: total organic carbon; TN: total nitrogen; $\mathrm{C} / \mathrm{N}$ : $\mathrm{C} / \mathrm{N}$ ratio.

\subsection{Experimental Design}

Given that these fields had been treated using straw return for the three preceding years of cultivation, it was not necessary to prepare the field for the current analysis. The fresh cucumber residue was crushed and returned directly to the field at approximately $120 \mathrm{t} /$ ha after removing the cucumber seedlings in June 2020. Dried chicken manure was sprinkled as a base fertility at a rate of $12 \mathrm{t} / \mathrm{ha}$, and was plowed with soil and straw to accelerate fermentation. Dried chicken manure was added to the soil as a swelling agent, and various doses of the microbial agents were then added to promote the degradation of the straw after it was crushed. Our experiments used a randomized block design with a total of four treatments, including a control treatment (no microbial agent) (CT), a treatment with $150 \mathrm{t}$ /ha microbial agents (CR1), a treatment with $300 \mathrm{t} /$ ha microbial agents (CR2), and a treatment with $450 \mathrm{t} /$ ha microbial agents (CR3). Each treatment was repeated three times. To ensure that the samples were representative of the composting system, multipoint samples were collected from different points at 3,7,10,17, 24, and 31 days. Then these samples were evenly mixed and divided into two subsamples of equal parts, one for testing the physical and chemical parameters, and the other for DNA extraction. All samples were stored in a low-temperature environment of $-80^{\circ} \mathrm{C}$ prior to analysis. 


\subsection{Analyses}

\subsubsection{Chemical and Physical Analyses}

An IEDA-T3 environmental temperature detector was applied, using a soil temperature probe buried at a depth of $10 \mathrm{~cm}$ from the surface to measure the soil temperature during the composting period, with the temperature data being recorded automatically every 30 min during this time.

The basic physicochemical properties of the soil were analyzed and evaluated using the method described by Bao [32]. The total organic carbon (TOC) content was determined using the potassium dichromate method, and the total nitrogen (TN) content was determined using the Kjeldahl method. The $\mathrm{C} / \mathrm{N}$ ratio describes the ratio between the TOC and the TN content. The $\mathrm{pH}$ and electrical conductance (EC) values of the composts (composting material: distilled water $=1: 10, w / v$ ) were obtained using a $\mathrm{pH}$ meter and a conductivity meter, respectively, while the soil water content was measured by the drying method. About $50 \mathrm{~g}$ of the soil sample was taken and put in an aluminum box, and then heated at $105^{\circ} \mathrm{C}$ to constant weight.

\subsubsection{Soil DNA Extraction and PCR Amplification}

The soil microbiome DNA was extracted using the Power Soil DNA Isolation Kit (MoBio Laboratories, Carlsbad, CA, USA). The quality and concentration of the DNA was determined using $1 \%$ agarose gel electrophoresis and spectrophotometry. Then, the extracted genomic DNA was used as a template to amplify the hypervariable V3-V4 region of the 16S rDNA genes of the fine bacteria using primer sequences 338F (ACTCCTACGGGAGGCAGCAG) and 806R (GGACTACNNGGGTATCTAAT), and the fungal ITS1 region was amplified using ITS1F (CTTGGTCATTTAGAGGAAGTAA) and ITS2R (TGCGTTCTTCATCGATGC). The reaction conditions for PCR amplification were as follows: 5 min of pre-denaturation at $95^{\circ} \mathrm{C}$, followed by 28 cycles of $45 \mathrm{~s}$ of denaturation at $95^{\circ} \mathrm{C}, 50 \mathrm{~s}$ of annealing at $55^{\circ} \mathrm{C}$, and $45 \mathrm{~s}$ of extension at $72^{\circ} \mathrm{C}$; a final extension of $10 \mathrm{~min}$ at $72{ }^{\circ} \mathrm{C}$ was also applied. Products were then preserved at $4{ }^{\circ} \mathrm{C}$ before sequencing.

\subsubsection{Next Generation Sequencing}

The PCR products were detected using $2 \%$ agarose gel electrophoresis. These products were then used to construct the microbial diversity sequencing library and subjected to paired-end sequencing using an Illumina MiseqPE300 high-throughput sequencing platform.

\subsection{Statistical Analysis}

The off-machine data were evaluated using QIIME1 software, and Vsearch was applied to remove sequences with lengths of less than $50 \mathrm{bp}$ after splicing. The Uchime method was used to compare de-chimera sequences according to the Gold Database, and forward operational taxonomic unit (OTU) clustering was performed based on $97 \%$ similarity [33].

The alpha diversity values for both the bacterial and fungal communities within each soil sample were calculated using QIIME software and evaluated using the community diversity indices Chao1, Shannon, and PD whole tree. Beta diversity analysis was used to evaluate differences in species complexity between the samples and was completed using the distance matrix in QIIME1 [34]. The data were then subjected to heat map clustering and principal coordinates analysis ( $\mathrm{PCoA})$, using a weighted UniFrac distance in R Software.

SPSS19.0 software was used to analyze the significant differences in the physicochemical properties of the soil in response to different treatments, while one-way ANOVA and multiple comparative analysis (Duncan) were used to set the significance level of the soil physicochemical properties. Canoco 4.5 was used to analyze the relationship between the soil physicochemistry and microbial communities using redundancy analysis (RDA). 


\section{Results}

\subsection{Composting Properties}

\subsubsection{Changes in Soil Temperature and Water Content}

Temperature is one of the most significant factors affecting the composting process, often reflecting the activity of soil microbes and their utilization of the organic matter in the environment. It can also be used as an index for the innocuity and stabilization of composting products. The results show that the overall pattern in the temperature change associated with the compositing process remained consistent across the various treatments, with all groups demonstrating a rapid increase in temperature between Days 0 and 3. However, the groups treated with exogenous microbial agents experienced rapid fermentation. The composting temperature after the application of microbial agents was higher than that of the CT group across the entire high-temperature period of composting fermentation. The composting temperature in the tillage layer began to decrease and gradually approached the ambient temperature after 20 days of composting. This suggests that the addition of exogenous microbial agents induces increases in the fermentation temperature and contributes to the rapid ripening of compost. The water content in all treatments gradually decreased with prolonged composting. Compared with the CT, the water content of CR1, CR2, and CR3 decreased faster, which may be related to the temperature (Figure 1).
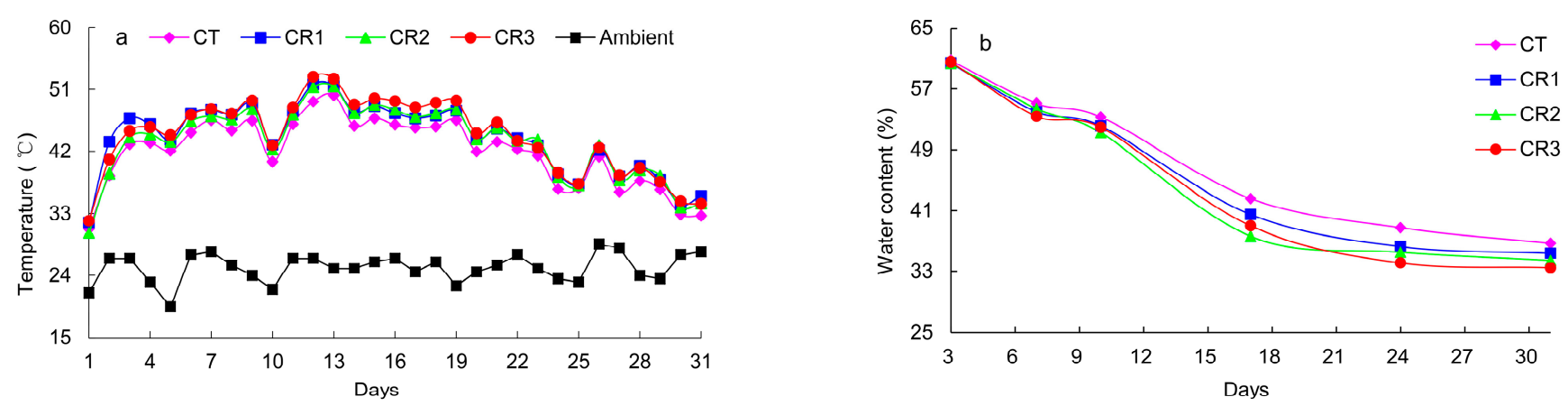

Figure 1. Changes in soil (a) temperature and (b) water content during composting.

\subsubsection{Changes in $\mathrm{pH}$ and $\mathrm{EC}$}

It is generally believed that the most suitable $\mathrm{pH}$ for composting is neutral or weakly alkaline. Figure 2a shows that the $\mathrm{pH}$ values in the CR1 and CR3 treatments first decreased and then increased in the initial stages but gradually decreased as the composting process continued. The $\mathrm{pH}$ values in the CR2 treatment group gradually decreased and then moved into the neutral range toward the end of the process. The $\mathrm{pH}$ values in the CT group increased at first and then decreased rapidly during the initial phase of fermentation, increasing slightly and then decreasing gradually as the composting process progressed. The $\mathrm{pH}$ in all treatments ranged from 7.0 to 7.5 , suggesting an environment that was suitable for biological growth and compost maturation The EC values from all the treatment groups suggest that the addition of exogenous microbial agents does not affect the soluble salt content in these reactions. The CR1, CR2, and CR3 groups reached their maximal concentration slightly earlier than the control, at Day 24, which may be the result of the addition of the microbial agents and increased mineralization of the organic matter in these systems. These values all declined after this point, and the final EC value of each treatment stabilized between 1.5 and 2.5 (Figure $2 \mathrm{~b}$ ).

\subsubsection{Changes in TOC and TN Content}

The TOC content gradually decreased in all treatment groups with CR1, CR2, and CR3 treatments demonstrating the most significant decrease in organic carbon content. This was likely because these groups had a larger number of active thermophilic microorganisms, which facilitated the rapid degradation of large amounts of easily decomposed 
organic carbon (Figure 3). The organic carbon content in the CT, CR1, CR2, and CR3 groups decreased by $43.6 \%, 53.1 \%, 58.4 \%$, and $53.7 \%$ across the entire composting process, respectively. The organic carbon content in CR2 was shown to experience the largest decrease, followed by CR3, CR2, and CT. The change in the TN content during composting is shown in Figure 3b. At the initial stage of composting, the TN content in CR1, CR2, and CR3 decreased slightly. After 10 days of composting, the TN content in the soil gradually increased with composting, compared with the initial stage of composting, with the TN content increasing by $18.6 \%, 13.1 \%, 31.6 \%$, and $21.3 \%$ in the CT, CR1, CR2, and CR3 groups, respectively. An appropriate $\mathrm{C} / \mathrm{N}$ ratio is beneficial for microorganism growth within the reactors (Figure $3 \mathrm{c}$ ), and this value was the highest in the CR2 treatment group. However, none of the other groups demonstrated any significantly different values by Day 3 . This indicates that the amount of microbial agent added to $C R 2$ increased the $C / N$ ratio within the reactor, which may explain its improved performance in other tests. The $\mathrm{C} / \mathrm{N}$ ratio decreased markedly rapidly in the CT group between Days 17 and 31.
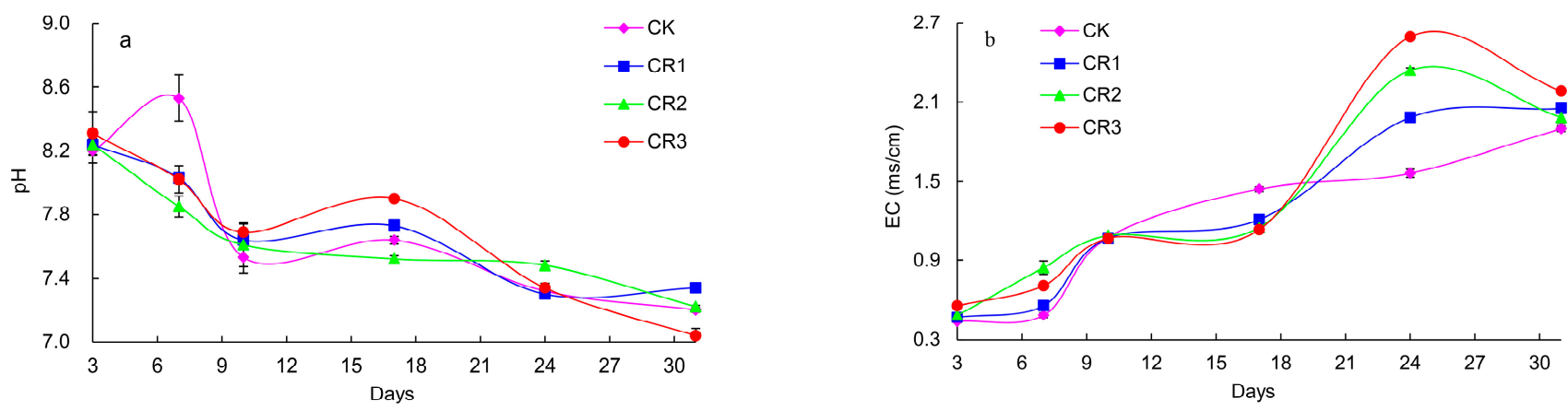

Figure 2. Changes in soil (a) $\mathrm{pH}$ and (b) EC values during composting.
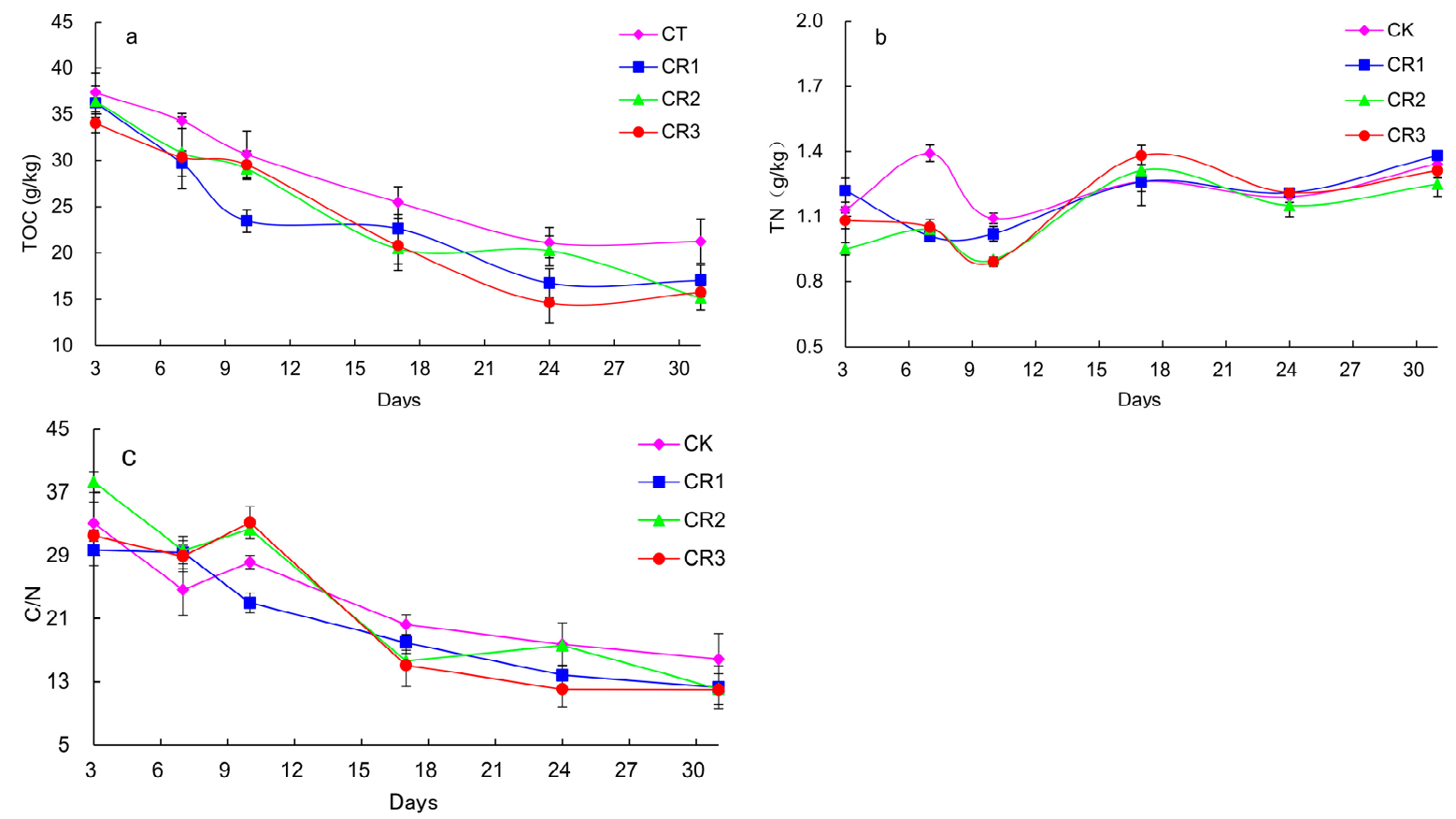

Figure 3. Changes in the (a) total organic carbon content, (b) total nitrogen content, and (c) $\mathrm{C} / \mathrm{N}$ ratio in the soil during composting. 


\subsection{Distribution of the Soil Microbiome}

\subsubsection{Predominant Bacterial and Fungal Taxa at the Phylum Level}

The predominant soil microbes after composting, with a relative abundance of more than $1 \%$ at the phylum level, were Proteobacteria, Chloroflexi, Actinobacteria, Firmicutes, Acidobacteria, Gemmatimonadetes, Bacteroidetes, Planctomycetes, and Deinococcus-Thermus. The relative abundance of Proteobacteria was the highest in the treatment groups (25.7-37.9\%), followed by Chloroflexi and Actinobacteria, with relative abundances of $14.1-21.8 \%$ and 8.9-13.9\%, respectively. The CR1, CR2, and CR3 treatments significantly increased the relative abundance of Firmicutes, which increased by $86.0 \%, 33.1 \%$, and $84.9 \%$, respectively. The relative performance of the four treatments was as follows: CR2 > CR3 > CT > CR1 (Figure 4a), when evaluating the relative abundance of Proteobacteria. There were only three fungal phyla whose relative abundance was more than $0.9 \%$. The relative abundances of Ascomycota, Mortierellomycota, and Basidiomycota were $81.5-96.0 \%, 1.0-16.4 \%$, and $0.9-1.4 \%$, respectively, while unnamed phyla accounted for $1.2-2.3 \%$ of the total. The relative abundance of Ascomycota differed between the groups, with the relative abundances being in the following order: CR1 > CR3 > CT > CR2. The relative abundance of Mortierellomycota was the highest in the CR2 treatment group (16.4\%) and lowest in the CR3 treatment group $(1.0 \%)$, while the relative abundance of Basidiomycota was the highest in the CR3 group $(2.3 \%)$ (Figure $4 b)$.
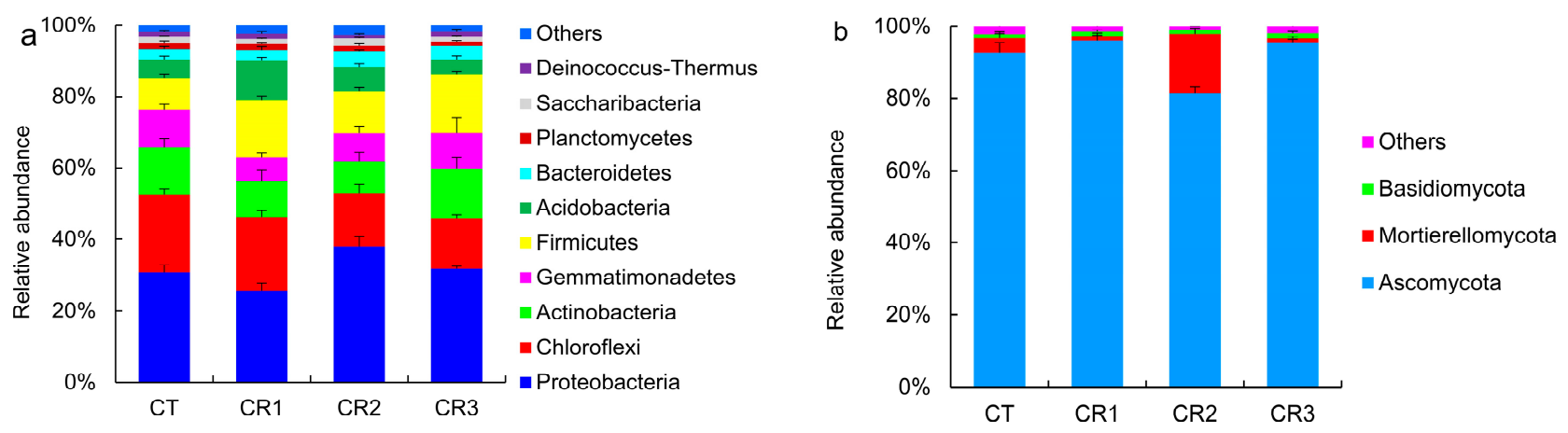

Figure 4. Composition and relative abundance of the (a) bacterial and (b) fungal communities at the phylum level after composting.

\subsubsection{Taxonomic Composition of Bacterial and Fungal Communities at the Genus Level}

The clustered tree for these data, produced using the unweighted pair group method with the arithmetic mean, was used to evaluate the differences between the treatment groups. The fungi and bacteria were markedly separate at the genus level with the predominant bacterial communities in the different stacks being Bacillus, Steroidobacter, Candidatus Chloroploca, Streptomyces, Pseudomonas, and Roseiflexus (Figure 5a). The relative abundance of the genera Bacillus and Steroidobacter increased notably in the treatment groups compared with the CT, ranging from $21.4 \%$ to $-87.1 \%$, and $23.4 \%$ to $-130.6 \%$, respectively, after composting. In addition, the predominant fungal genera were Mycothermus, Myceliophthora, Aspergillus, and Mortierella (Figure 5b). The relative abundance of Mycothermus decreased significantly by $35.6 \%, 42.4 \%$, and $42.4 \%$ after the CR1, CR2, and CR3 treatments, respectively, compared with the CT group. The relative abundance of Aspergillus was significantly increased by $674.7 \%$ in the CR2 group, and the relative abundance of Myceliophthora increased by $47.6 \%$ and $43.9 \%$ after the CR2 and CR3 treatments, respectively.

\subsection{Richness and Diversity of Bacterial and Fungal Communities in Soil Samples Following Composting}

OTU clustering was carried out using a $97 \%$ sequence similarity cut-off; the bacterial and fungal $\alpha$ diversity after the different treatments is shown in Table 2. The V3-V4 region of the 16S rRNA gene from soil bacteria and the ITS1 region in fungi were sequenced 
using next generation sequencing. A total of 345,801 effective sequences for the bacterial samples and 552,758 sequences for the fungal samples were obtained. The number of bacterial OTUs was significantly higher in the CR3 treatment group than in the CT group $(p<0.05)$. However, there were no significant differences in the number of OTUs among the CR1, CR2, and CT groups. The Chao1 index increased significantly in the CR2 group, but it decreased significantly in the CR1 and CR3 groups compared with the control. The $\mathrm{PD}$ whole tree index of the $\mathrm{CR} 2$ treatment was significantly higher than that of the other treatments, indicating that the CR2 treatment significantly increased bacterial abundance and community diversity. Fungal species richness (Chao1) and community diversity (PD whole tree and Shannon) significantly increased in the samples treated with increasing microbial agent concentrations compared to the $\mathrm{CT}$ samples.
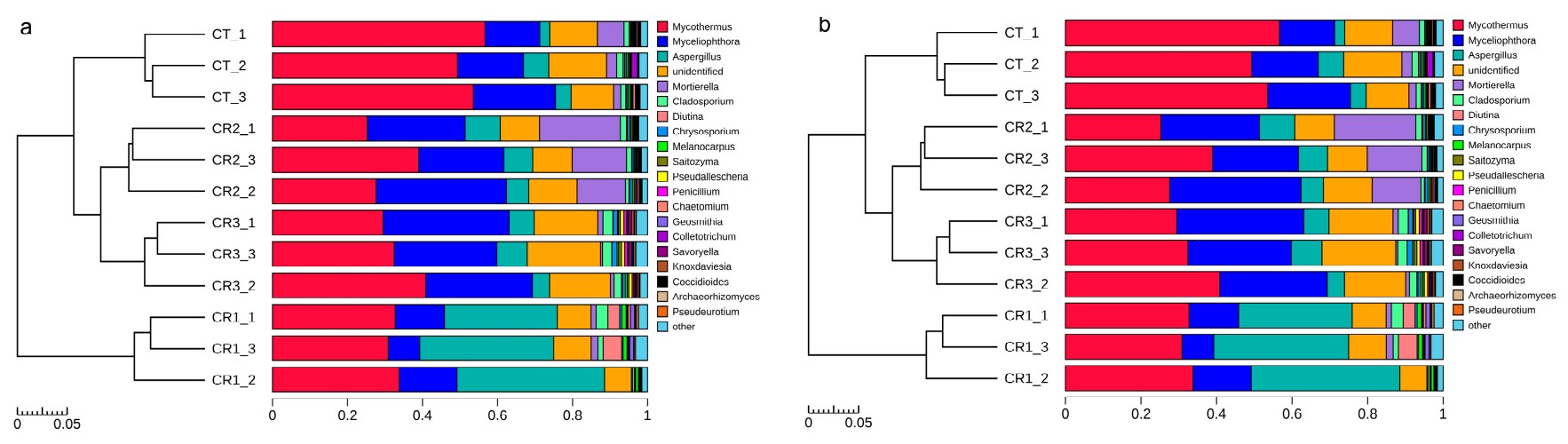

Figure 5. Composition and relative abundance of the (a) bacterial and (b) fungal communities at the genus level after composting.

Table 2. Effects of composting on the richness and diversity of the bacterial and fungal communities in the soil.

\begin{tabular}{|c|c|c|c|c|c|c|}
\hline & Processing & Clean Tags & OTUs & Chao1 & PD Whole Tree & Shannon \\
\hline \multirow{4}{*}{ Bacteria } & $\mathrm{CT}$ & $70841 \mathrm{~b}$ & $2201 \mathrm{~b}$ & $2856 \mathrm{~b}$ & $184.45 \mathrm{~b}$ & $8.84 \mathrm{a}$ \\
\hline & CR1 & $75231 \mathrm{~b}$ & $2299 \mathrm{ab}$ & $2725 c$ & $183.08 \mathrm{~b}$ & $8.87 \mathrm{a}$ \\
\hline & CR2 & 104396 a & $2249 a b$ & 2968 a & $197.54 \mathrm{a}$ & $8.92 \mathrm{a}$ \\
\hline & CR3 & 95333 a & $2404 \mathrm{a}$ & $2743 c$ & $177.95 \mathrm{~b}$ & $8.68 \mathrm{a}$ \\
\hline \multirow{4}{*}{ Fungi } & $\mathrm{CT}$ & 110437 c & $327 b$ & $342 \mathrm{~d}$ & $59.6 \mathrm{~d}$ & $3.49 \mathrm{~b}$ \\
\hline & CR1 & $141453 \mathrm{~b}$ & $260 c$ & $418 \mathrm{~b}$ & $68.38 \mathrm{~b}$ & $3.52 \mathrm{~b}$ \\
\hline & CR2 & $142419 \mathrm{~b}$ & $316 \mathrm{~b}$ & $589 a$ & $77.32 \mathrm{a}$ & $3.79 \mathrm{a}$ \\
\hline & CR3 & 158449 a & $392 \mathrm{a}$ & $395 c$ & $63.76 \mathrm{c}$ & $3.41 \mathrm{~b}$ \\
\hline
\end{tabular}

Different letters indicate significant differences among the samples by one-way ANOVA (Duncan, $p<0.05$ ).

\subsection{Treatment Effect on Bacterial and Fungal Beta Diversity}

Beta diversity analysis was used to evaluate the differences between the microbial communities. PCoA was used to compare and determine the factors influencing the microbial differences among the samples. The more similar the sample composition, the closer the distance in the PCoA chart. Principal Component 1 (PC1) and Principal Component 2 (PC2) explained $31.3 \%$ and $20.8 \%$ of the total bacterial variation (Figure $6 a$ ) as well as $50.5 \%$ and $20.4 \%$ of the total fungal variation (Figure $6 \mathrm{~b}$ ), respectively. The CR1, CR2, and CR3 treatments were significantly different from the CT in the bacterial analyses, indicating that the addition of microbial agents can result in changes in the soil bacterial community composition, especially after adding significant quantities of these microbial agents. There was a state of free separation between the CR1 treatment and other treatments in the fungal analyses, which suggest that the addition of a small quantity of a microbial agent could significantly affect the composition of the fungal community. 


\subsection{Relationship between Predominant Soil Microflora and Environmental Factors}

The relative abundance of both the bacterial and fungal communities and the environmental parameters associated with the predominant soil microflora were analyzed at the class level, using RDA (Figure 7a,b). This analysis was designed to identify the relationships between the various environmental factors and microflora in our soil samples. The microbial species codes are presented in Tables 3 and 4 . The cumulative explanatory variables of bacterial abundance distribution in the first and second axes represent $22.7 \%$ and $21.2 \%$ of the total variance, respectively. The cumulative explanatory variables in the fungal abundance distribution in the first and second axes represent $42.2 \%$ and $20.0 \%$ of the total variation, respectively. The relative abundance of the predominant microflora in the soil bacterial community correlated with various soil environmental factors, including the $\mathrm{TN}$ content, which explained $21.6 \%$ of the total variation, suggesting that the TN content was an important factor in determining the structure of the soil microbiome (Figure 7a). The TN content $(\mathrm{F}=2.80, p=0.036)$ also showed the strongest correlation with community composition in the fungal samples, but these communities were sensitive to temperature $(\mathrm{F}=2.80, p=0.034)$ and $\mathrm{pH}(\mathrm{F}=2.70, p=0.038)$, suggesting that a combination of these three factors was critical for determining the fungal community structure in this biome (Figure $7 b$ ).

Table 3. Bacterial species codes used in the redundancy analysis.

\begin{tabular}{cc}
\hline Number & Species \\
\hline & Proteobacteria \\
A1 & Alphaproteobacteria \\
A2 & Gammaproteobacteria \\
A3 & Betaproteobacteria \\
A4 & Deltaproteobacteria \\
& Firmicutes \\
B1 & Bacilli \\
B2 & Clostridia \\
& Actinobacteria \\
C1 & Actinobacteria \\
C2 & Acidimicrobiia \\
C3 & Thermomicrobia \\
& Chloroflexi \\
D1 & Anaerolineae \\
D2 & Chloroflexia \\
D3 & Gitt-GS-136 \\
\hline
\end{tabular}

Table 4. Fungal species codes used in the redundancy analysis.

\begin{tabular}{cc}
\hline Number & Species \\
\hline E1 & Ascomycota \\
E2 & Sordariomycetes \\
E3 & Eurotiomycetes \\
E4 & Dothideomycetes \\
E5 & Saccharomycetes \\
& Leotiomycetes \\
F1 & Mortierellomycota \\
& Mortierellomycetes \\
G1 & Basidiomycota \\
G2 & Tremellomycetes \\
\end{tabular}



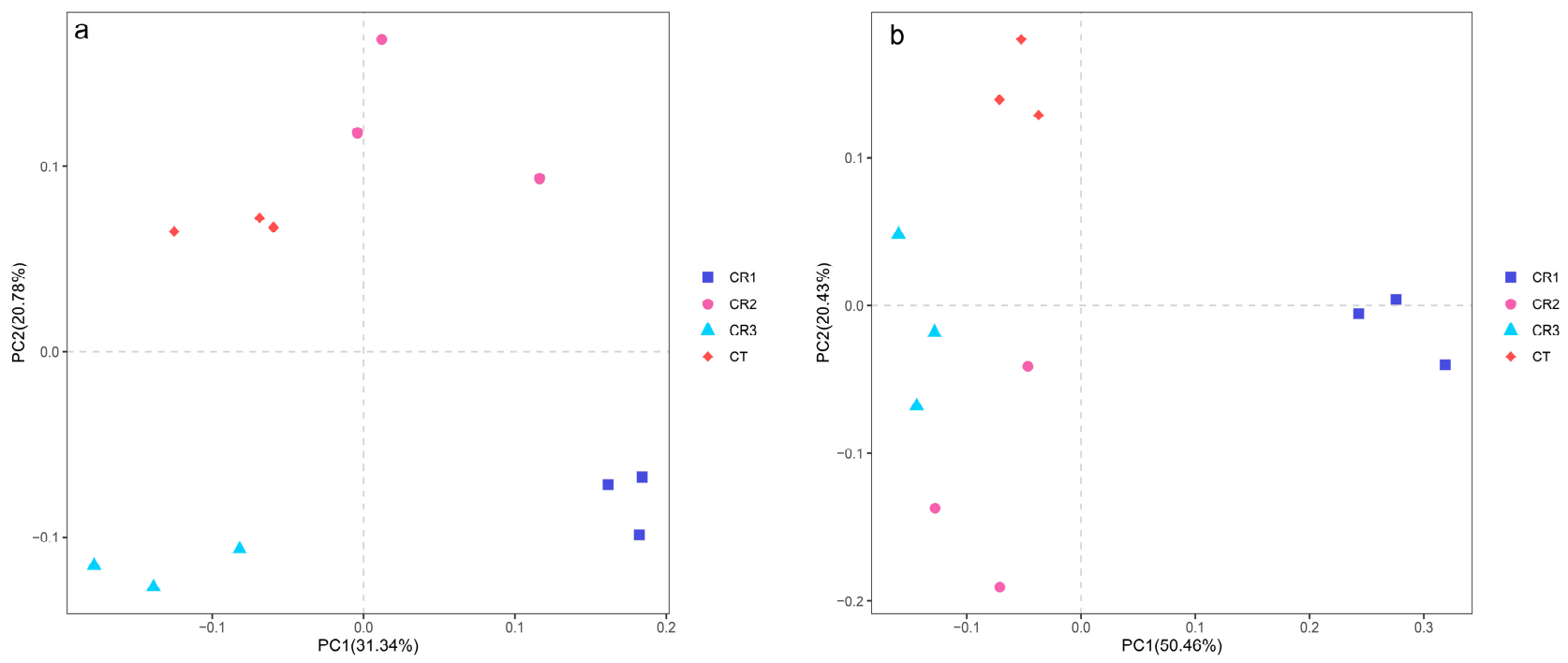

Figure 6. Principal component analysis of (a) bacterial and (b) fungal communities in the composting samples.
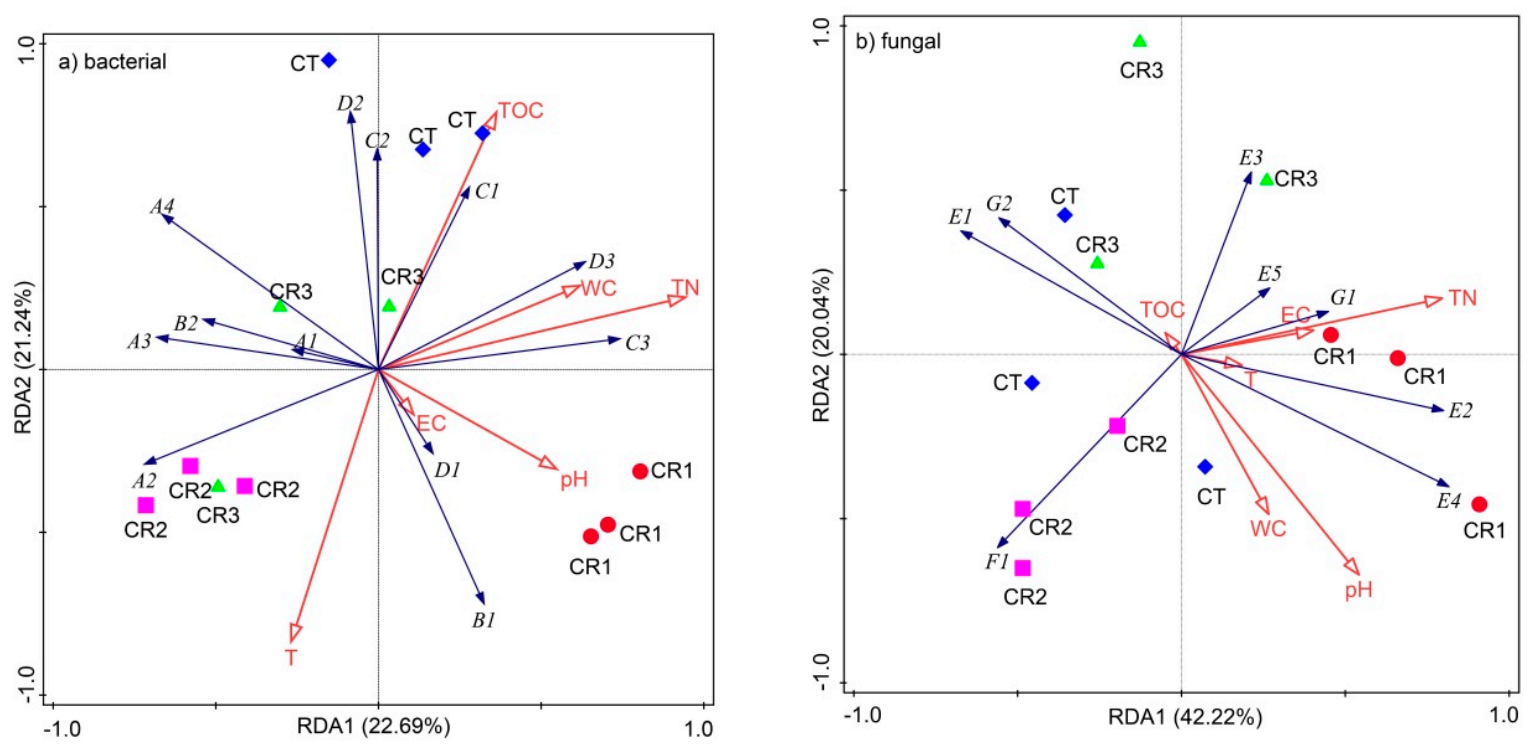

Figure 7. Redundancy analysis, describing the effects of various environmental factors on the community structure of both the (a) bacterial and (b) fungal populations following composting.

\section{Discussion}

4.1. Effect of Exogenous Microbial Agents on the Physicochemical Properties of Topsoil Composting

Temperature had a significant impact on the microbial community within the reactors, with high temperatures shown to be necessary to promote the innocuity and stabilization of the composting process [22]. The addition of exogenous microbial agents significantly increased the reactor temperature. Liu et al. [22] found that the addition of compound microbial agents could accelerate the degradation of organic matter during composting, resulting in the generation of more heat, and thus promoting an increase in reactor temperature. Zhang et al. [35] showed that the high temperatures produced during the composting process killed pathogens and insect eggs and affected the viability of weed seeds, helping to shape the predominant microbial community in the composted products. Water content also plays an important role in microorganism growth and reproduction during composting. In the present study, we found that the water content of the compost decreased gradually as the composting process continued. In addition, the water content in 
the samples treated with exogenous microbial agents decreased more rapidly than that of the control, with these decreases likely the result of the metabolic activity of the exogenous microbial agents in these treatments. The addition of these agents also increased the overall activity of the microbiome and accelerated the ripening process.

The composting process is affected by $\mathrm{pH}$, which can impair or accelerate the growth of the microorganisms needed to complete this process [36,37]. According to the $\mathrm{pH}$ values, each sample was alkaline during the initial stages of composting. However, with the decomposition and ripening of the composting materials and concurrent production of organic acids, a gradual decrease in $\mathrm{pH}$ value and its stabilization was observed, reaching a plateau between the values of 7.0 and 7.5 at the end of the composting period [38]. These results were consistent with those of previous studies that described the addition of cellulose to green waste and straw composting $[39,40]$. The EC value can be used to determine the concentration of soluble salts in soil, and high EC can damage plants, leading to soil degradation [41]. Here, we found that the EC value first increased and then began to decrease rapidly, finally stabilizing at a value between 1.5 and $2.5 \mathrm{~ms} / \mathrm{cm}$ when the composting reaction was complete, which is in agreement with the results reported by Liu et al. [42], all of which met the suitable EC value that marks compost maturity of less than $4 \mathrm{~ms} / \mathrm{cm}$ [43].

The results show that the TN content in each heap increased when the compost was decomposed and that the TN content in the compost samples treated with exogenous microbial agents was lower than that of the control at the end of composting. This may be because the addition of the microbial agents increased the composting temperature, allowing more nitrogen to leach into the soil as volatile ammonia [44]. Chen et al. [45] showed that this loss of nitrogen was related to its conversion into various other forms $\left(\mathrm{NO}_{3}-\mathrm{N}, \mathrm{NO}_{2}-\mathrm{N}, \mathrm{NO}\right.$, and $\left.\mathrm{N}_{2}\right)$. In addition, the organic carbon content of soil treated with microbial agents (CR1, CR2, and CR3) after composting decreased significantly by $20.1 \%, 28.8 \%$, and $25.9 \%$, respectively, compared with the CT. This was consistent with the results reported by Li et al. [46]. Harshitha et al. argued that all C/N ratios between 10 and 21 indicate that the pile has reached the maturity standard [47]. In the current study, on the 17th day, CR1, CR2, and CR3 reached maturity, with a $\mathrm{C} / \mathrm{N}$ ratio ranging from 15 to 18 , indicating that the compost had reached the maturity standard. This suggests that the addition of exogenous microbial agents can promote composting maturity under these conditions.

\subsection{Effects of Exogenous Microbial Agents on the Bacterial and Fungal Communities}

The distribution characteristics of both the bacterial and fungal microbial communities described in this study suggest that there are distinct differences, at the phylum level, in samples treated with various doses of exogenous microbial agents. Our results show that changing the microbial dose resulted in changes in the prevalence of the phyla Proteobacteria, Chloroflexi, Actinobacteria, Firmicutes, and Acidobacteria, as well as Ascomycetes. The richness and diversity of these soil communities were shown to increase most significantly when treated using CR2. Sun et al. showed that a high diversity of the bacterial community during composting made the microbial community more conducive to the decomposition of straw and chicken manure. Highly diverse bacterial communities are also an ideal environment for identifying heat-tolerant strains of composting microbes [48]. Our experiments showed that the addition of B. subtilis and B. licheniformis to the exogenous microbial inoculum significantly increases the relative abundance of Bacillus. Zhao et al. found that Bacillus could metabolize nutrients using organic substances, such as cellulose and pectin, which were difficult to decompose during periods of high temperatures, indicating that these bacteria promoted the decay and stabilization of the pile. The predominant flora in the fungal community in the piles changed significantly after the cucumber straw was returned to the field enriched with microbial agents, and the relative abundance of Mortierellomy cota increased significantly following the CR2 treatment. After composting, the relative abundance of Mycothermus decreased significantly when the pile was initially treated 
with microbial agents, which was consistent with the results reported by Zhang et al. [49]. Natvig et al. [50] found that Mycothermus was a thermophilic fungus that could produce the thermostable enzyme lignocellulase, which dominates the high-temperature period of composting and plays a role in the degradation of lignocellulose.

\subsection{Correlation between Bacterial and Fungal Communities and the Physicochemical Properties of the Soil}

The structure of the soil microbiome is closely linked to the environment that they reside in, and the interactions between the members within the community and between the members and environmental factors are important in shaping the community diversity [51-53]. In the current study, we found a correlation between the dominant microflora structures and the environmental factors associated with these samples after composting. RDA and Monte Carlo simulation demonstrated that the soil TN content had the most significant effect on both the bacterial and fungal communities, which was consistent with the results of Li et al. [23]. This is because the strains of Firmicutes that decompose the nitrogenous organic compounds in compost into nitrogen sources can be absorbed and utilized by plants. Nitrogen sources can promote the growth and development of crops. Temperature was a major factor in establishing microbial communities, as temperature can affect the heterotrophic respiration of microorganisms by changing enzyme activity, microbial respiration rate, and the availability of the substrate $[54,55]$.

\section{Conclusions}

1. The addition of exogenous microbial agents to cucumber straw during the in situ processing of these samples aided the aerobic fermentation process necessary to initiate the composting reaction in the plow layer. The results demonstrated that the addition of exogenous microbial agents prolong the high-temperature duration, reduce the total organic carbon (TOC) content, and accelerated the decline in the $\mathrm{C} / \mathrm{N}$ ratio, ensuring compost maturity and effectively shortening the composting time.

2. Proteobacteria, Chloroflexi, Actinobacteria, Firmicutes, and Acidobacteria were the dominant phyla in the bacterial community structure. Compared with the CT, the CR1, CR2, and CR3 treatments significantly increased the relative abundance of Firmicutes. For the fungal community, the CR2 treatment significantly increased the relative abundance of Mortierellomycota but decreased the relative abundance of Ascomycota. Moreover, the addition of exogenous microbial agents can significantly increase the richness and diversity of the fungal community.

3. Redundancy analysis (RDA) revealed that the total nitrogen (TN) content was the most predominant main factor affecting the composition of the bacterial community, while the TN content, $\mathrm{pH}$, and temperature were the most important factors that determined the fungal community composition.

Author Contributions: Data curation, C.Y. (Cuixia Yun); Methodology, C.Y. (Changrong Yan), Y.X. and Z.X.; Writing—original draft, C.Y. (Cuixia Yun); Writing—review \& editing, C.Y. (Changrong Yan), T.J. and Q.L. All authors have read and agreed to the published version of the manuscript.

Funding: This research was supported by the Zero-Waste Agricultural Mulch Films for Crops in China project (Newton Fund: Newton UK-China Agritech Challenge 2017; No. 2017YFE0121900), Talent Project of Imported Technology in European Functional Agricultural Film (2020), Central Public-Interest Scientific Institution Basal Research Fund (Y2019LM02-06; BSRF201909). We gratefully acknowledge the anonymous reviewers for their valuable comments on the manuscript.

Institutional Review Board Statement: Not applicable.

Informed Consent Statement: Not applicable.

Data Availability Statement: Not applicable. 
Acknowledgments: We gratefully acknowledge Chaowu Ding from Shouguang Huilianzhitong Agricultural Science and Technology Co., Ltd. for his data curation and the anonymous reviewers for their valuable comments on the manuscript.

Conflicts of Interest: The authors declare no conflict of interest.

\section{References}

1. Turmel, M.-S.; Speratti, A.; Baudron, F.; Verhulst, N.; Govaerts, B. Crop residue management and soil health: A systems analysis. Agric. Syst. 2015, 134, 6-16. [CrossRef]

2. He, J.-Z.; Zheng, Y.; Chen, C.-R.; He, Y.-Q.; Zhang, L.-M. Microbial composition and diversity of an upland red soil under long-term fertilization treatments as revealed by culture-dependent and culture-independent approaches. J. Soils Sediments 2008, 8, 349-358. [CrossRef]

3. Zhang, H.; Ding, W.; He, X.; Yu, H.; Fan, J.; Liu, D. Influence of 20-year organic and inorganic fertilization on organic carbon accumulation and microbial community structure of aggregates in an intensively cultivated sandy loam soil. PLoS ONE 2014, 9, e92733. [CrossRef] [PubMed]

4. Alvarez, R.; Lidén, G. Semi-continuous co-digestion of solid slaughterhouse waste, manure, and fruit and vegetable waste. Renew. Energy 2008, 33, 726-734. [CrossRef]

5. Mahmoud, M.; Elreedy, A.; Pascal, P.; Sophie, L.R.; Tawfik, A. Hythane (H2 and CH4) production from unsaturated polyester resin wastewater contaminated by 1,4-dioxane and heavy metals via up-flow anaerobic self-separation gases reactor. Energy Convers. Manag. 2017, 152, 342-353. [CrossRef]

6. Das, A.; Mondal, C. Studies on the utilization of fruit and vegetable waste for generation of biogas. Int. J. Eng. Sci. 2013, 3, 24-32.

7. Gale, W.J.; Cambardella, C.A. Carbon dynamics of surface residue- and root-derived organic matter under simulated no-till. Soil Sci. Soc. Am. J. 2000, 64, 190-195. [CrossRef]

8. Arcand, M.M.; Knight, J.D.; Farrell, R.E. Differentiating between the supply of N to wheat from above and belowground residues of preceding crops of pea and canola. Biol. Fertil. Soils 2014, 50, 563-570. [CrossRef]

9. Ibrahim, M.; Cao, C.G.; Zhan, M.; Li, C.-F.; Iqbal, J. Changes of CO2 emission and labile organic carbon as influenced by rice straw and different water regimes. Int. J. Environ. Sci. Technol. 2013, 12, 263-274. [CrossRef]

10. Briassoulis, D.; Dejean, C. Critical review of norms and standards for biodegradable agricultural plastics Part I. Biodegradation in soil. J. Polym. Environ. 2010, 18, 384-400. [CrossRef]

11. Andrea, C.; Muniyasami, S.; Emo, C. Assessment of the whole environmental degradation of oxo-biodegradable linear low density polyethylene (LLDPE) films designed for mulching applications. J. Polym. Environ. 2012, 20, 1007-1018.

12. Kyrikou, I.; Briassoulis, D. Biodegradation of agricultural plastic films: A critical review. J. Polym. Environ. 2007, 15, 125-150. [CrossRef]

13. Wang, J.; Luo, Y.; Teng, Y.; Ma, W.; Christie, P.; Li, Z. Soil contamination by phthalate esters in Chinese intensive vegetable production systems with different modes of use of plastic film. Environ. Pollut. 2013, 180, 265-273. [CrossRef]

14. Liu, E.K.; He, W.Q.; Yan, C.R. 'White revolution' to 'white pollution'-Agricultural plastic film mulch in China. Environ. Res. Lett. 2014, 9, 024010. [CrossRef]

15. Zhang, D.; Liu, H.-B.; Hu, W.-L.; Qin, X.-H.; Ma, X.-W.; Yan, C.-R.; Wang, H.-Y. The status and distribution characteristics of residual mulching film in Xinjiang, China. J. Integr. Agric. 2016, 15, 2639-2646. [CrossRef]

16. Kasirajan, S.; Ngouajio, M. Polyethylene and biodegradable mulches for agricultural applications: A review. Agron. Sustain. Dev. 2012, 32, 501-529. [CrossRef]

17. Tan, Z.; Yi, Y.; Wang, H.; Zhou, W.; Yang, Y.; Wang, C. Physical and degradable properties of mulching films prepared from natural fibers and biodegradable polymers. Appl. Sci. 2016, 6, 147. [CrossRef]

18. Dahman, Y.; Ugwu, C.U. Production of green biodegradable plastics of poly(3-hydroxybutyrate) from renewable resources of agricultural residues. Bioprocess Biosyst. Eng. 2014, 37, 1561-1568. [CrossRef]

19. Cozzolino, E.; Giordano, M.; Fiorentino, N.; El-Nakhel, C.; Pannico, A.; Di Mola, I.; Mori, M.; Kyriacou, M.C.; Colla, G.; Rouphael, Y. Appraisal of biodegradable mulching films and vegetal-derived biostimulant application as eco-sustainable practices for enhancing lettuce crop performance and nutritive value. Agronomy 2020, 10, 427. [CrossRef]

20. Zang, X.Y.; Liu, M.; Wang, H.; Fan, Y.; Zhang, H.; Liu, J.; Xing, E.; Xu, X.; Li, H. The distribution of active beta-glucosidase producing microbial communities in composting. Can. J. Microbiol. 2017, 63, 998-1008. [CrossRef] [PubMed]

21. Yogev, A.; Raviv, M.; Hadar, Y.; Cohen, R.; Wolf, S.; Gil, L.; Katan, J. Induced resistance as a putative component of compost suppressiveness. Biol. Control. 2010, 54, 46-51. [CrossRef]

22. Liu, N.; Hou, T.; Yin, H.; Han, L.; Huang, G. Effects of amoxicillin on nitrogen transformation and bacterial community succession during aerobic composting. J. Hazard. Mater. 2019, 362, 258-265. [CrossRef] [PubMed]

23. Li, C.; Li, H.; Yao, T.; Su, M.; Li, J.; Liu, Z.; Xin, Y.; Wang, L.; Chen, J.; Gun, S. Effects of microbial inoculation on enzyme activity, available nitrogen content, and bacterial succession during pig manure composting. Bioresour. Technol. 2020, 306, 123167. [CrossRef]

24. Yin, Y.; Gu, J.; Wang, X.; Tuo, X.; Zhang, K.; Zhang, L.; Guo, A.; Zhang, X. Effects of copper on the composition and diversity of microbial communities in laboratory-scale swine manure composting. Can. J. Microbiol. 2018, 64, 409-419. [CrossRef] 
25. Ma, S.; Fang, C.; Sun, X.; Han, L.; He, X.; Huang, G. Bacterial community succession during pig manure and wheat straw aerobic composting covered with a semi-permeable membrane under slight positive pressure. Bioresour. Technol. 2018, 259, $221-227$. [CrossRef]

26. Liu, N.; Zhou, J.; Han, L.; Ma, S.; Sun, X.; Huang, G. Role and multi-scale characterization of bamboo biochar during poultry manure aerobic composting. Bioresour. Technol. 2017, 241, 190-199. [CrossRef]

27. Mao, H.; Lv, Z.; Sun, H.; Li, R.; Zhai, B.; Wang, Z.; Awasthi, M.K.; Wang, Q.; Zhou, L. Improvement of biochar and bacterial powder addition on gaseous emission and bacterial community in pig manure compost. Bioresour. Technol. 2018, 258, 195-202. [CrossRef]

28. Wu, J.; He, S.; Liang, Y.; Li, G.; Li, S.; Chen, S.; Nadeem, F.; Hu, J. Effect of phosphate additive on the nitrogen transformation during pig manure composting. Environ. Sci. Pollut. Res. 2017, 24, 17760-17768. [CrossRef]

29. Zhang, L.; Sun, X. Changes in physical, chemical, and microbiological properties during the two-stage co-composting of green waste with spent mushroom compost and biochar. Bioresour. Technol. 2014, 171, 274-284. [CrossRef]

30. Ren, G.; Xu, X.; Qu, J.; Zhu, L.; Wang, T. Evaluation of microbial population dynamics in the co-composting of cow manure and rice straw using high throughput sequencing analysis. World J. Microbiol. Biotechnol. 2016, 32, 1-11. [CrossRef]

31. Huang, C.; Zeng, G.; Huang, D.; Lai, C.; Xu, P.; Zhang, C.; Chen, Z.; Wan, J.; Hu, L.; Zhang, Y. Effect of Phanerochaete chrysosporium inoculation on bacterial community and metal stabilization in lead-contaminated agricultural waste composting. Bioresour. Technol. 2017, 243, 294-303. [CrossRef] [PubMed]

32. Bao, S.D. Soil and Agricultural Chemistry Analysis; China Agriculture Press: Beijing, China, 2000.

33. Haas, B.J.; Gevers, D.; Earl, A.M.; Feldgarden, M.; Ward, D.V.; Giannoukos, G.; Ciulla, D.; Tabbaa, D.; Highlander, S.K.; Sodergren, E.; et al. Chimeric 16S rRNA sequence formation and detection in Sanger and 454-pyrosequenced PCR amplicons. Genome Res. 2011, 21, 494-504. [CrossRef]

34. Lozupone, C.A.; Hamady, M.; Kelley, S.T.; Knight, R. Quantitative and qualitative beta diversity measures lead to different insights into factors that structure microbial communities. Appl. Environ. Microbiol. 2007, 73, 1576-1585. [CrossRef]

35. Zhang, L.; Sun, X.; Tian, Y.; Gong, X. Effects of brown sugar and calcium superphosphate on the secondary fermentation of green waste. Bioresour. Technol. 2013, 131, 68-75. [CrossRef]

36. Hoshino, Y.T.; Morimoto, S. Comparison of $18 \mathrm{~S}$ rDNA primers for estimating fungal diversity in agricultural soils using polymerase chain reaction-denaturing gradient gel electrophoresis. Soil Sci. Plant Nutr. 2008, 54, 701-710. [CrossRef]

37. Awasthi, M.K.; Wang, Q.; Chen, H.; Wang, M.; Ren, X.; Zhao, J.; Li, J.; Guo, D.; Li, D.-S.; Awasthi, S.K.; et al. Evaluation of biochar amended biosolids co-composting to improve the nutrient transformation and its correlation as a function for the production of nutrient-rich compost. Bioresour. Technol. 2017, 237, 156-166. [CrossRef]

38. Sun, D.; Lan, Y.; Xu, E.G.; Meng, J.; Chen, W. Biochar as a novel niche for culturing microbial communities in composting. Waste Manag. 2016, 54, 93-100. [CrossRef]

39. Zhang, L.; Sun, X. Effects of earthworm casts and zeolite on the two-stage composting of green waste. Waste Manag. 2015, 39, 119-129. [CrossRef]

40. Abdel-Rahman, M.A.; El-Din, M.N.; Refaat, B.M.; Abdel-Shakour, E.H.; Ewais, E.E.-D.; Alrefaey, H.M. Biotechnological application of thermotolerant cellulose-decomposing bacteria in composting of rice straw. Ann. Agric. Sci. 2016, 61, 135-143. [CrossRef]

41. Sharifi, Z.; Sinegani, A.A.S. Arsenic and other irrigation water quality indicators of ground water in an agricultural area of Qorveh Plain, Kurdistan, Iran. Am. Eurasian J. Agric. Environ. Sci. 2012, 12, 548-555.

42. Liu, L.; Wang, S.; Guo, X.; Zhao, T.; Zhang, B. Succession and diversity of microorganisms and their association with physicochemical properties during green waste thermophilic composting. Waste Manag. 2018, 73, 101-112. [CrossRef]

43. Awasthi, M.K.; Pandey, A.K.; Khan, J.; Bundela, P.S.; Wong, J.W.; Selvam, A. Evaluation of thermophilic fungal consortium for organic municipal solid waste composting. Bioresour. Technol. 2014, 168, 214-221. [CrossRef]

44. Zhao, Y.; Lu, Q.; Wei, Y.; Cui, H.; Zhang, X.; Wang, X.; Shan, S.; Wei, Z. Effect of actinobacteria agent inoculation methods on cellulose degradation during composting based on redundancy analysis. Bioresour. Technol. 2016, 219, 196-203. [CrossRef]

45. Chen, W.; Liao, X.; Wu, Y.; Liang, J.B.; Mi, J.; Huang, J.; Zhang, H.; Wu, Y.; Qiao, Z.; Li, X.; et al. Effects of different types of biochar on methane and ammonia mitigation during layer manure composting. Waste Manag. 2017, 61, 506-515. [CrossRef]

46. Li, C.; Li, H.; Yao, T.; Su, M.; Ran, F.; Han, B.; Li, J.; Lan, X.; Zhang, Y.; Yang, X.; et al. Microbial inoculation influences bacterial community succession and physicochemical characteristics during pig manure composting with corn straw. Bioresour. Technol. 2019, 289, 121653. [CrossRef]

47. Harshitha, J.; Krupanidhi, S.; Kumar, S.; Wong, J. Design and development of indoor device for recycling of domestic vegetable scrap. Environ. Technol. 2015, 37, 326-334. [CrossRef] [PubMed]

48. Hou, N.; Wen, L.; Cao, H.; Liu, K.; An, X.; Li, D.; Wang, H.; Du, X.; Li, C. Role of psychrotrophic bacteria in organic domestic waste composting in cold regions of China. Bioresour. Technol. 2017, 236, 20-28. [CrossRef] [PubMed]

49. Zhang, W.H.; Men, M.; Xu, B.; Xu, X.; Cheng, L.; Meng, Q.; Deng, L.; Jiang, X.; Wu, X.; Sheng, S. Dynamic characteristics of the composition of the fungal community in a novel static composting system of dairy manure and rice straw. J. Agro-Environ. Sci. 2018, 37, 2029-2036.

50. Natvig, D.O.; Taylor, J.W.; Tsang, A.; Hutchinson, M.I.; Powell, A.J. Mycothermus thermophilus gen. et comb. nov., a new home for the itinerant thermophile Scytalidium thermophilum (Torula thermophila). Mycologia 2015, 107, 319-327. [CrossRef] [PubMed] 
51. Ranjard, L.; Dequiedt, S.; Jolivet, C.; Saby, N.P.A.; Thioulouse, J.; Harmand, J.; Loisel, P.; Rapaport, A.; Fall, S.; Simonet, P.; et al. Biogeography of soil microbial communities: A review and a description of the ongoing french national initiative. Agron. Sustain. Dev. 2010, 30, 359-365. [CrossRef]

52. Roy, K.; Ghosh, D.; Debruyn, J.M.; Dasgupta, T.; Wommack, K.E.; Liang, X.; Wagner, R.E.; Radosevich, M. Temporal dynamics of soil virus and bacterial populations in agricultural and early plant successional soils. Front. Microbiol. 2020, 11, 1494. [CrossRef]

53. Liang, X.; Wagner, R.E.; Li, B.; Zhang, N.; Radosevich, M. Quorum sensing signals alter in vitro soil virus abundance and bacterial community composition. Front. Microbiol. 2020, 11, 1287. [CrossRef] [PubMed]

54. Suseela, V.; Conant, R.T.; Wallenstein, M.D.; Dukes, J.S. Effects of soil moisture on the temperature sensitivity of heterotrophic respiration vary seasonally in an old-field climate change experiment. Glob. Change Biol. 2011, 18, 336-348. [CrossRef]

55. Frey, S.; Drijber, R.; Smith, H.; Melillo, J. Microbial biomass, functional capacity, and community structure after 12 years of soil warming. Soil Biol. Biochem. 2008, 40, 2904-2907. [CrossRef] 